\title{
Hybrid Taguchi Based Grey Algorithm for Multi Objective Optimization of Gas Metal Arc Welded DP1000 Steel
}

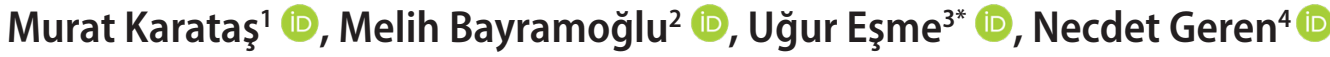 \\ 'Gedik Welding Company, Turkey \\ ${ }^{2,4}$ Cukurova University, Department of Mechanical Engineering, Adana, Turkey \\ ${ }^{3}$ Tarsus University, Department of Mechanical Engineering, Mersin, Turkey
}

\begin{abstract}
Euro-6 norms for reduction of $\mathrm{CO}_{2}$ emissions and ECE-R66-01 regulation for safer passenger transportation became legislative obligations for bus builders. These two adaptations increase the weight of a bus as nearly $600 \mathrm{~kg}$ which also increases the fuel consumption nearly $1.5-3 \%$. Dual phase (DP) steels can compensate these increases by decreasing the thickness of the components. Because, ferrite provides the steel with good formability and martensite increases the hardness and ultimate tensile strength in DP steels. This study focused on the multi response hybrid optimization of gas metal arc welding (GMAW) of DP1000 steel to determine the optimal parametric combination which gives the maximum ultimate tensile strength (UTS, MPa) and joint efficiency (JE) under minimum heat input $(\mathrm{Q}, \mathrm{kj} / \mathrm{mm})$. Nine experimental trials which is based on the orthogonal array suggested by Taguchi method was carried out to investigate objective functions for optimization in the experimental range of GMAW parameters such as voltage ( $\mathrm{U}$, volt), welding speed $(\mathrm{V}, \mathrm{mm} / \mathrm{min}$ ) and wire feed rate (f, $\mathrm{m} / \mathrm{min}$ ). The Taguchi method continued with Grey Relational Analysis (GRA) to overcome the multiobjective optimization model. Finally, Analysis of variance (ANOVA) method has been used to determine the significance of the welding parameters on the responses of UTS, JE and Q. This shows flexible applicability of Taguchi based GRA to find out the effect of each GMAW process parameters onto individual responses.
\end{abstract}

Keywords: DP1000 steel, Taguchi method, Gas Metal arc welding, Grey relation optimization

\section{INTRODUCTION}

The passenger safety, comfort and the fuel consumption are the most significant commercial factors for bus builders. While the global demand for fuel consumption is increasing, some standards such as Euro-6 norms for reduction of CO2 emissions and ECE-R66-01 regulation for safer passenger transportation become legislative obligations for bus builders [1]. These two adaptations increase the weight of a bus structure as nearly $600 \mathrm{~kg}$ which also increases the fuel consumption nearly $1.5-3 \%$. The most effective methods to compensate this increase in fuel consumptions without any loss on passenger safety and comfort can be improved by redesigning bus body aerodynamics, chemical changes on the consumed fuel, engine efficiency improvement, and reduction on the structure weight. Among these applications, reducing the vehicle weight is the most effective and applicable method for fuel economy [1].

Reducing the weight includes redesigning the bus body structure and use of higher strength to weight ratio steels.
Unfortunately, geometrical design changes on bus structure have limited potential to compensate the weight increase which is caused by the legislative obligations. Thus, the best way to compensate the weight increase is decreasing the thickness of the parts by using higher strength structural steels.

Gas metal arc welding (GMAW) process produces an electric arc between a consumable wire electrode and the workpieces to melt and join base materials. The filler metal is fed automatically from the wire feeder mechanism, through a liner, then out of a contact tip in the torch. In this process, $\mathrm{CO}_{2}$ or mixture gas (combinations of $\mathrm{Ar}, \mathrm{He}, \mathrm{CO}_{2}$ and $\mathrm{O}_{2}$ ) are used to prevent oxidation and diffusion of $\mathrm{H}_{2}$ and $\mathrm{N}_{2}$ to the molten metal. GMAW process can be applied semi-automatic or fully automatic. Figure 1 shows the basic schematic representation of GMAW process.

The GMAW process is mostly performed on lower grades of DP steels such as DP480 and DP600, however, it can also be used to weld higher strength grades (DP780, DP1000).
* Corresponding author

Email: esme@tarsus.edu.tr
European Mechanical Science (2021), 5(4): 206-213

doi: https://doi.org/10.26701/ems.941934

Received: May 24, 2021

Accepted: August 31, 2021 


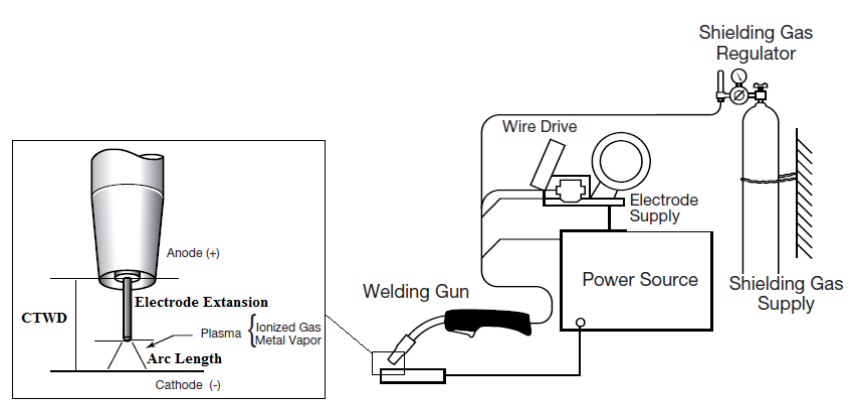

Figure 1. A general schematic representation of a GMAW system [2]

But, martensite tempering percentage and decrease in UTS increase with higher grade DP steel usage at the same heat input. However, GMAW is the mostly applied technique in bus building industry, because it is the fastest and most applicable welding method for joining of rectangular cross-sectional profiles [1]. Literature survey shows that there are various studies in the literature dealing with modeling and optimization of GMAW using different kind of workpiece materials and optimization techniques. Martinez et al. [3] developed a framework for the prediction of weld bead and penetration geometry in GMAW process using deep learning and machine learning techniques. Huang et al. [4] proposed ensemble empirical mode decomposition with adaptive noise and extreme learning machine for online control the weld quality diagnosis of GMAW process. Sivasakthivelet. al. [5] developed a back propagation neural network model for the prediction of bead geometry in gas metal arc welded stainless steel plates. Chauhan et al. [6] used Taguchi technique in GMAW process for optimization of gas metal arc welded AISI 1018 mild steel plates. Aghakhani et al. [7] optimized GMAW process by Taguchi method on weld dilution. Kumar et al. [8] implemented the Taguchi method followed by grey relation analysis to optimize gas metal arc welding process parameters for multi performance characteristics of bead width and height, weld penetration and heat affected zone using AISI 1020 steel. Rizvi et al. [9] investigated the optimization for SS304H steel using Taguchi based grey relational analysis. Arya et al. [10] showed the influence of welding parameters in metal inert gas welding process using Taguchi based grey relation analysis. Esme et al. [11] optimized quality characteristics of the tungsten inert gas welding parameters such as weld bead, weld height, penetration, heat affected zone and ultimate tensile strength using Taguchi combined grey relational analysis method. Srivastava et al. [12] used Box Behnken design technique of Response Surface Methodology to optimize gas metal arc welding for IS 2062 mild steel. Singla et al. [13] developed a mathematical model for the parametric optimization of gas metal arc welding by using factorial design approach. Ambekar et al. [14] presented a study by using Taguchi orthogonal array of $\mathrm{L}_{16}$ for optimization of process parameters gas metal arc welding on AISI 410 steel. Yadav et al. [15] made parametric optimization tensile strength in GMAW by performing Taguchi method. Sreeraj et al. [16] made an optimization study for gas metal arc welding parameters using central composite rotatable design and particle swarm method. Shao et al. [17] developed a mathematical model using design of experiments and polynomial regression method for modeling and optimization of gas metal arc welding method. Kshirsagar et al. [18] used Hybrid Nelder Mead-Evolutionary algorithms to develop a model for optimization purpose and comparison of this method with the others.

The Taguchi method proposed by Genichi Taguchi in 1950s is very famous and fast tool to improve and solve optimization of in all kind of manufacturing process [11,19]. This technique offers an opportunity to design the experiments called orthogonal design matrix with a minimum number of trials. The approach also uses the signal to noise ratio $(\mathrm{S} / \mathrm{N})$ to serve the objective role within the experimental range to be optimized (maximized). On the other hand, Taguchi method alone cannot solve the multi objective optimization problem. Taguchi method combined with GRA may overcome this problem and solve the multi-response designed problems in a wide range of engineering applications. Taguchi technique successfully uses orthogonal arrays to build the experiments in optimization.

In the present study, it is aimed to determine the optimum process parameters such as welding voltage (U, volt), welding speed $(\mathrm{V}, \mathrm{mm} / \mathrm{min})$ and wire feed rate $(\mathrm{f}, \mathrm{m} / \mathrm{min})$ in GMAW process to generate required weld quality in respect of ultimate tensile strength (UTS, MPa), joint efficiency (JE) and heat input $\mathrm{Q}(\mathrm{kj} / \mathrm{mm})$. Hybrid combination of grey relation analysis and Taguchi approach for multi objective optimization has been performed to determine the optimum process condition for GMAW process. Finally, the analysis of variance (ANOVA) and confirmation test were applied in order to examine the contribution of each welding factors and to check the optimum results.

\section{GREY RELATIONAL ANALYSIS APPROACH AND TERMINOLOGY}

Although the black region of the grey relational analysis (GRA) contains no information, the white region contains information completely. The grey system, on the other hand, denotes the degree of detail between white and black. In other words, while some information is known in the grey system, but some is unknown. GRA is one of the subtitles of grey modeling. The each factor in the system compared with reference sequence to determine the relationship degree between the factors [19].

First, experimental data is normalized starting from zero to one according to the normalization criterions: i. smaller-the-better, ii. Larger-the-better and iii. ideal-the-better. This is named as Grey relational generation. Grey relational coefficient (GRC) for each experimental level is then determined using normalized values in order to find the relationship in between actual and desired data. Averaging the corresponding GRC for the selected response yields the overall Grey relational grade (GRG). So, GRG which is also performance characteristic of the multiple response is converted 
Table 1. Mechanical properties and chemical composition (wt.\%) of DP1000 steel [20]

\begin{tabular}{|c|c|c|c|c|c|c|c|}
\hline $\begin{array}{c}\text { Chemical composition } \\
\text { (wt. \%) }\end{array}$ & $\mathrm{Si}$ & $\mathrm{P}$ & $\mathrm{C}$ & $\mathrm{Mn}$ & $\mathrm{Nb}$ & $\mathrm{S}$ & $\mathrm{Al}$ \\
\cline { 2 - 8 } & 0.50 & 0.01 & 0.15 & 1.50 & 0.015 & 0.02 & 0.04 \\
\hline \multirow{2}{*}{$\begin{array}{c}\text { Mechanical properties } \\
\text { Tensile strength }(\mathrm{MPa})\end{array}$} & \multicolumn{2}{|c|}{ Yield strength $(\mathrm{MPa})$} & Hardness $\left(\mathrm{HV}_{0.5}\right)$ & Elongation (\%) \\
\cline { 2 - 7 } & \multicolumn{2}{|c|}{1000} & 1000 & 320 & 7 \\
\hline
\end{tabular}

into a single response optimization [11,19]. The highest GRG in the system is the optimal parametric combination. Lastly, Taguchi method is applied to maximize the overall GRG for optimal parameter setting.

In Grey relational generation calculation of this work, the larger-the-better (LB) criterion is used to calculate the normalized reference sequences for ultimate tensile strength and joint efficiency. LB criterion is expressed as [19]:

$$
x_{i}(k)=\frac{y_{i}(k)-\min y_{i}(k)}{\max y_{i}(k)-\min y_{i}(k)}
$$

Heat input relates to the smaller-the-better (SB) criterion. It is expressed as:

$$
x_{i}(k)=\frac{\max y_{i}(k)-y_{i}(k)}{\max y_{i}(k)-\min y_{i}(k)}
$$

hereby, $x_{i}(k)$ is determined after GRG, $\min y_{i}(k)$ is the lowest $y_{i}(k)$ value associated with the $k^{\text {th }}$ response, and $\max y_{i}(k)$ is the highest $y_{i}(k)$ value related to the $k^{\text {th }}$ response. For the responses, the reference series is $x_{0}(k)(k=1,2,3 \ldots . ., 9)$. In the process of GRG analysis, the concept of the grey relational degree is to demonstrate the degree of the relationship between 9 sequences $\left[x_{0}(k)\right.$ and $\left.x_{i}(k), \mathrm{i}=1,2,3 \ldots \ldots ., 9\right]$. The relational coefficient of grey (GRC) is measured as [19]:

$$
\xi_{i}(k)=\frac{\Delta_{\min }+\psi \Delta_{\max }}{\Delta_{0 i}(k)+\psi \Delta_{\max }}
$$

hereby, $\Delta_{0 i}=\left\|x_{0}(k)-x_{i}(k)\right\|$ is the absolute value difference between $x_{0}(k)$ and $x_{i}(k) ; \psi$ is the distinguishing multiplier $0 \leq \psi \leq 1 ; \Delta_{\text {min }}=\forall j^{\min } \in i \forall k^{\min }\left\|x_{0}(k)-x_{j}(k)\right\|$ is the lowest value of $\Delta_{0 i}$; and $\Delta_{\text {max }}=\forall j^{\max } \in i \forall k^{\max }\left\|x_{0}(k)-x_{j}(k)\right\|$ is the highest value of $\Delta_{0 i}$. After taking the mean of coefficients of Grey relational analysis, the GRG $\gamma_{i}$ is calculated as [19]:

$$
\gamma_{i}=\frac{1}{n} \sum_{k=1}^{n} \xi_{i}(k)
$$

hereby, the number of welding responses is expressed by $n$. The higher the GRG value, the greater the relation between the given sequence $x_{i}(k)$ and comparison sequence. The best sequence is the reference sequence $x_{0}(k)$; hence, a higher GRG indicates that the acquired parameter combination is approaching the optimum value. Both the GRG main effect graph and the average response for the GRG are extremely important in deciding the optimum welding process conditions [19].

\section{MOTIVATION AND EXAMINATION RESULTS OF EXPERIMENTS}

\subsection{Description of Experiments}

The purpose of this study is multi objective optimization of GMAW process parameters for improving mechanical properties of DP1000 steel joint [1]. For this aim, the effects of GMAW parameters on mechanical performance and welding quality of $1.2 \mathrm{~mm}$ DP1000 plates were investigated. The dimensions of the DP1000 plates and welding design were defined depending on TS 6868-1 EN 287-1 standard. Therefore, 300x150 mm dimensions of DP1000 steel plates were used for butt welding. The mechanical properties and chemical composition (wt.\%) of the used workpiece material is depicted in Table 1.

An automated GMAW system was designed and built to provide consistent linear welds and to eliminate the welding defects, which can be caused by the welder. In this way, free wire length was kept constant. The components of welding automation system used in this study is shown in Figure 2.

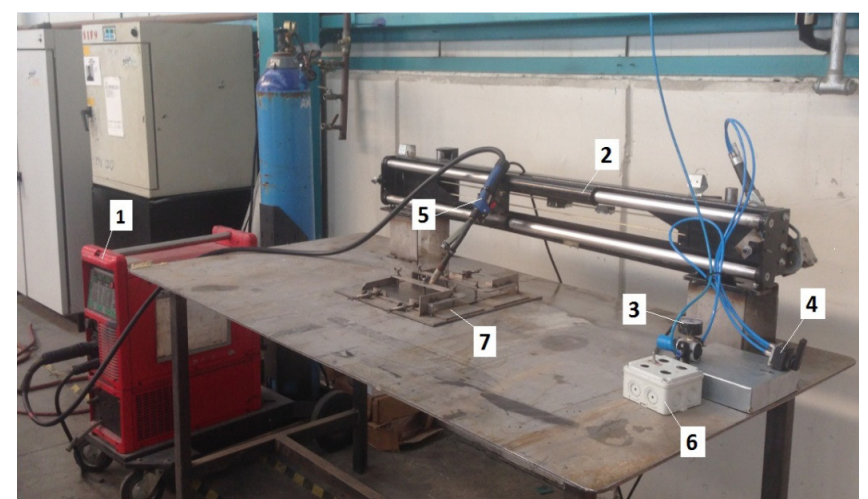

Figure 2. Components of the automated welding system used for experimental work: (1) Fronius Transpuls Synergic 2700 welding power supply, (2) Pneumatic welding automation mechanism, (3) Pneumatic valve to control welding speed, (4) Pneumatic valve to control welding start/stop and direction, (5) GMAW torch, (6) Welding arc start/stop control panel and (7) Welding fixture

Fronius Transpuls Synergic 2700 welding power supply, which had 270A current capacity is employed for welding applications. The welding wire is selected as $0.8 \mathrm{~mm}$ and ER70S-6 (AWS 5.18) standard.100\% $\mathrm{CO}_{2}$ under the constant flow rate of $8 \mathrm{~L} / \mathrm{min}$ is used as a shielding gas. Also, direct current electrode positive (DCEP) polarity is utilized for better penetration, arc stability, higher electrode melting rates and lower heat input to workpiece. The welding current start and stop functions are controlled with an adapted on/off switch panel. The welding automation system is propelled using a pneumatic activation system which is used to adjust welding speed (valve-3) and direction (valve-4). In order to prevent lost welding designs due to the welding deformation, a workpiece clamping fixture is produced as shown in Figure 3. 


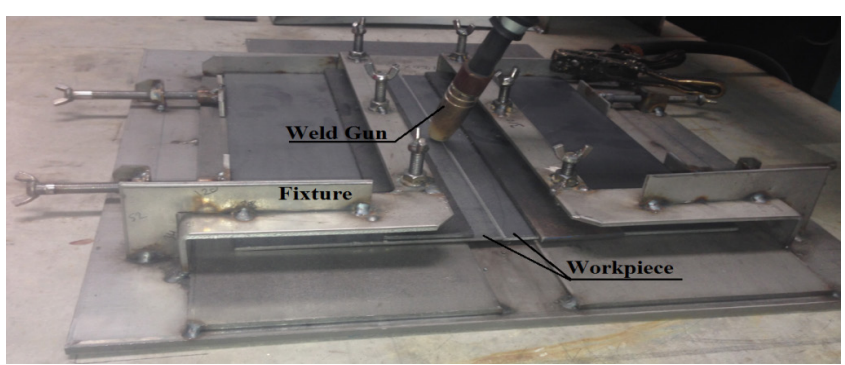

Figure 3. Welding fixture used in the experiments

Samples which is prepared according to transverse tensile test method of EN 895 were taken from the weld zone centered in the gage length. After, they were loaded to tensile test machine to measure the ultimate tensile strength.

\subsection{Experimental Procedure and Results}

In a full factorial experimental plan, increasing the number of parameters and their levels raises the cost, time and especially experimental runs exponentially $[11,19]$. In order to avoid these negative effects under a limited number of experimental runs, Taguchi's $\mathrm{L}_{9}$ orthogonal array, which consists of 9 data sets, was used.

Experimental runs have been carried out in according to the welding parameters illustrated in Table 2 given below. Welding current ( $\mathrm{I}, \mathrm{A})$ was adjusted according to the wire feed rate level; for $\mathrm{f}_{1}=2.20 \mathrm{~m} / \mathrm{min} \mathrm{I}=45 \mathrm{~A}, \mathrm{f}_{2}=2.40 \mathrm{~m} / \mathrm{min} \mathrm{I}=53 \mathrm{~A}$ and for $\mathrm{f}_{3}=2.60 \mathrm{~m} / \mathrm{min} \mathrm{I}=60 \mathrm{~A}$.

Table 2. Level of GMAW parameters

\begin{tabular}{|c|c|c|c|c|c|}
\hline \multirow{2}{*}{ Welding parameters } & \multirow{2}{*}{ Notation } & \multirow{2}{*}{ Unit } & \multicolumn{3}{|c|}{ Parameter Levels } \\
\cline { 4 - 6 } & $\mathrm{U}$ & volt & 1 & 2 & 3 \\
\hline Voltage & $\mathrm{V}$ & $\mathrm{mm} / \mathrm{min}$ & $260^{*}$ & 18.50 & 19.50 \\
\hline Welding speed & $\mathrm{f}$ & $\mathrm{m} / \mathrm{min}$ & $\begin{array}{c}2.20^{*} \\
(\mathrm{I}=45 \mathrm{~A})\end{array}$ & $\begin{array}{c}2.40 \\
(\mathrm{I}=53 \mathrm{~A})\end{array}$ & $\begin{array}{c}2.60^{*} \\
(\mathrm{I}=60 \mathrm{~A})\end{array}$ \\
\hline Wire feed & & & & \\
\hline
\end{tabular}

Energy generated by the power source $\mathrm{E}(\mathrm{kj} / \mathrm{mm})$ can be calculated as [20]:

$$
E=\frac{U x I x 60}{V x 1000}
$$

where $\mathrm{U}=$ Voltage (Volt), $\mathrm{I}=$ Current $(\mathrm{A})$ and $\mathrm{V}=$ Welding Speed $(\mathrm{mm} / \mathrm{min})$.
In order to calculate the heat input more accurately, the arc efficiency $(\eta)$ is taken as 0.8 for the present GMAW welding process. Finally, the following formula is used for calculating the welding heat input $(\mathrm{Q}, \mathrm{kj} / \mathrm{mm})[20]$;

$$
Q=\eta x E
$$

The ratio of the strength of a welded joint to the strength of the used base material is known as joint efficiency (JE). $\mathrm{L}_{9}$ Taguchi's orthogonal array that shows the 9 sets of coded experimental condition corresponding to UTS, JE and $\mathrm{Q}$ are shown in Table 3. For the evaluation of the optimum GMAW parameter combination needed to overcome the required weld quality within the studied region, all these data were used for grey relationship analysis.

The welding samples of DP1000 steel were visually inspected according to EN ISO 3834 standard [1]. Therefore, Level- $\mathrm{C}$ which has medium tolerances for imperfections was used as a guide on the quality levels of butt welding. Some of the visual inspected workpieces and their categorization is illustrated in Figure 4.
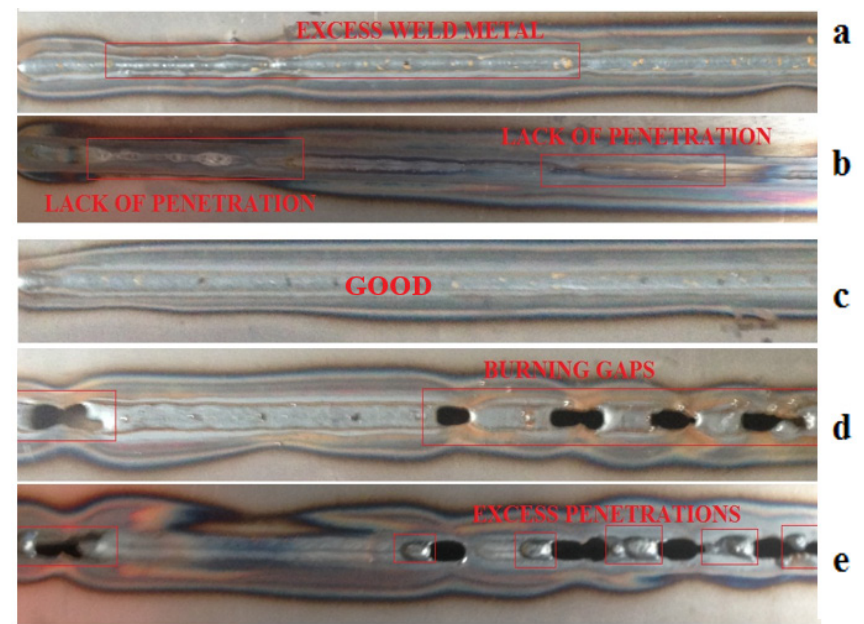

Figure 4. Visual categorization of weld inspection of the samples: (a) Excess weld metal, (b) Lack of penetration, (c) Good, (d) Burning gaps, (e) Excess penetration

\section{GRA OPTIMIZATION OF GMAW PARAMETERS}

\subsection{Evaluation of Optimal Welding Condition}

First, measured and calculated data is normalized for grey

\begin{tabular}{|c|c|c|c|c|c|c|c|c|}
\hline \multirow{3}{*}{ Run no } & \multicolumn{3}{|c|}{ Process parameter levels } & \multicolumn{5}{|c|}{ Experimental results } \\
\hline & \multirow{2}{*}{$\mathrm{U}$} & \multirow{2}{*}{ V } & \multirow{2}{*}{$f$} & \multirow{2}{*}{$\begin{array}{c}\text { UTS } \\
(\mathrm{MPa})\end{array}$} & \multirow{2}{*}{$J E$} & \multirow{2}{*}{$\begin{array}{c}\mathrm{Q} \\
(\mathrm{kj} / \mathrm{mm})\end{array}$} & \multicolumn{2}{|c|}{ Visual weld inspection } \\
\hline & & & & & & & Cap & Root \\
\hline 1 & 1 & 1 & 1 & 794.125 & 0.794 & 0.145 & Good & Good \\
\hline 2 & 1 & 2 & 2 & 795.785 & 0.796 & 0.139 & Burning gap & Lack of Penetration \\
\hline 3 & 1 & 3 & 3 & 797.215 & 0.797 & 0.133 & Good & Good \\
\hline 4 & 2 & 1 & 2 & 772.995 & 0.772 & 0.181 & Burning gap & Good \\
\hline 5 & 2 & 2 & 3 & 786.235 & 0.786 & 0.167 & Good & Good \\
\hline 6 & 2 & 3 & 1 & 808.04 & 0.808 & 0.105 & Good & Burning gap \\
\hline 7 & 3 & 1 & 3 & 772.905 & 0.772 & 0.216 & Burning gap & Excess penetration \\
\hline 8 & 3 & 2 & 1 & 796.715 & 0.796 & 0.132 & Burning gap & Excess penetration \\
\hline 9 & 3 & 3 & 2 & 801.095 & 0.801 & 0.131 & Good & Good \\
\hline
\end{tabular}

Table 3. $L_{9}$ Orthogonal array and corresponding experimental and calculated results 
relation generation by using Eqs. (1) and (2) [11,19]. For each of the responses, the normalized data and the difference in absolute value $\left(\Delta_{0 i}\right)$ were calculated and presented in Table 4 and Table 5 , respectively.

Table 4. Normalization of the responses

\begin{tabular}{|c|c|c|c|}
\hline \multirow{2}{*}{ Exp. run } & UTS & JE & Q \\
\cline { 2 - 4 } & larger-the-better & larger-the-better & smaller-the-better \\
\hline Reference series & 1.000 & 1.000 & 1.000 \\
\hline 1 & 0.604 & 0.611 & 0.640 \\
\hline 2 & 0.651 & 0.667 & 0.694 \\
\hline 3 & 0.692 & 0.694 & 0.748 \\
\hline 4 & 0.003 & 0.000 & 0.315 \\
\hline 5 & 0.379 & 0.389 & 0.441 \\
\hline 6 & 1.000 & 1.000 & 1.000 \\
\hline 7 & 0.000 & 0.000 & 0.000 \\
\hline 8 & 0.678 & 0.667 & 0.757 \\
\hline 9 & 0.802 & 0.806 & 0.766 \\
\hline
\end{tabular}

Table 5. $\Delta_{0 i}$ for each responses

\begin{tabular}{|c|c|c|c|}
\hline Exp. run & UTS & JE & Q \\
\hline Reference series & 1 & 1 & 1 \\
\hline 1 & 0.396 & 0.389 & 0.360 \\
\hline 2 & 0.349 & 0.333 & 0.306 \\
\hline 3 & 0.308 & 0.306 & 0.252 \\
\hline 4 & 0.997 & 1.000 & 0.685 \\
\hline 5 & 0.621 & 0.611 & 0.559 \\
\hline 6 & 0.000 & 0.000 & 0.000 \\
\hline 7 & 1.000 & 1.000 & 1.000 \\
\hline 8 & 0.322 & 0.333 & 0.243 \\
\hline 9 & 0.198 & 0.194 & 0.234 \\
\hline
\end{tabular}

Distinguishing coefficient $(\psi)$ is ranged between 0 and 1 . Literature review shows that distinguishing factor does not affect the grey relational grade [8]. In this study it is taken as equal weight of 0.333 for each responses as $\psi_{U T S}=\psi_{\boldsymbol{E}}=\psi_{Q}=$ 0.333. The determined Grey relational coefficients (GRC) for each response using Eq (3) are shown in Table 6.

Table 6. GRC for each responses

\begin{tabular}{|c|c|c|c|}
\hline Exp. run & UTS & JE & Q \\
\hline$\psi$ & 0.333 & 0.333 & 0.333 \\
\hline 1 & 0.457 & 0.461 & 0.480 \\
\hline 2 & 0.488 & 0.500 & 0.521 \\
\hline 3 & 0.519 & 0.521 & 0.569 \\
\hline 4 & 0.250 & 0.250 & 0.327 \\
\hline 5 & 0.349 & 0.353 & 0.374 \\
\hline 6 & 1.000 & 1.000 & 1.000 \\
\hline 7 & 0.250 & 0.250 & 0.250 \\
\hline 8 & 0.508 & 0.500 & 0.578 \\
\hline 9 & 0.628 & 0.631 & 0.587 \\
\hline
\end{tabular}

Then, it is followed by calculation of grey relational grade (GRG) which shows the total representative value of the responses. The multi-criteria optimization problem of the GMAW method is thus reduced to a basic optimization model using the Taguchi combined GRA. In this section, it should be noted that a higher GRG indicates that the factor combination is close to its optimal value. Table 7 shows the calculated GRG and their grade.

Table 7. GRG and their rank

\begin{tabular}{|c|c|c|}
\hline Exp. run & GRG & Ranking \\
\hline 1 & 0.466 & 6 \\
\hline 2 & 0.503 & 5 \\
\hline 3 & 0.536 & 3 \\
\hline 4 & 0.275 & 8 \\
\hline 5 & 0.358 & 7 \\
\hline 6 & 0.999 & 1 \\
\hline 7 & 0.250 & 9 \\
\hline 8 & 0.528 & 4 \\
\hline 9 & 0.615 & 2 \\
\hline
\end{tabular}

Now, the signal to noise $(\mathrm{S} / \mathrm{N})$ related to the larger-the-better criteria for overall GRG for each experiment is calculated using Eq. (7) [19]. Converted GRG into S/N ratio is presented in Table 8.

$$
S / N=-10 \log \left[\frac{1}{n} \sum_{i=1}^{n} \frac{1}{y_{i}^{2}}\right]
$$

hereby, $y_{i}$ is the experimental value $i^{\text {th }}$ response in the $j^{\text {th }}$ experiment at the $k^{\text {th }}$ test, and $n$ denotes the number of measurements.

Table 8. Mean grey grade and corresponding $\mathrm{S} / \mathrm{N}$ ratios

\begin{tabular}{|c|c|c|}
\hline Exp. run & $\mathrm{S} / \mathrm{N}$ & Mean grey grade \\
\hline 1 & -6.632 & 0.466 \\
\hline 2 & -5.969 & 0.503 \\
\hline 3 & -5.417 & 0.536 \\
\hline 4 & -11.213 & 0.275 \\
\hline 5 & -8.922 & 0.358 \\
\hline 6 & -0.009 & 0.999 \\
\hline 7 & -12.041 & 0.250 \\
\hline 8 & -5.547 & 0.528 \\
\hline 9 & -4.222 & 0.615 \\
\hline
\end{tabular}

The highest $\mathrm{S} / \mathrm{N}$ ratio means the optimum parameter setting for related process is in the experimental domain. Since a high $\mathrm{S} / \mathrm{N}$ value has a much greater effect on responses than the noise factors of the random effects. Graphical representation of $\mathrm{S} / \mathrm{N}$ ratio and GRG versus parameter level is given in Figure 5. The average of the GRG and $\mathrm{S} / \mathrm{N}$ ratio on the plots symbolized as dashed line.

As shown in Figure 4, the optimal parameter combination for GMAW welding of DP1000 steel joint becomes $U_{1} V_{3} f_{1}$. Corresponding each level of average results for GRG and $\mathrm{S} / \mathrm{N}$ ratios is presented in Table 9.

Delta statistics which is formulated as the maximum value minus minimum value indicates the relative size of each effect. According to delta analysis; welding speed has the highest rank value, wire feed and welding voltage have second and third rank values respectively. 


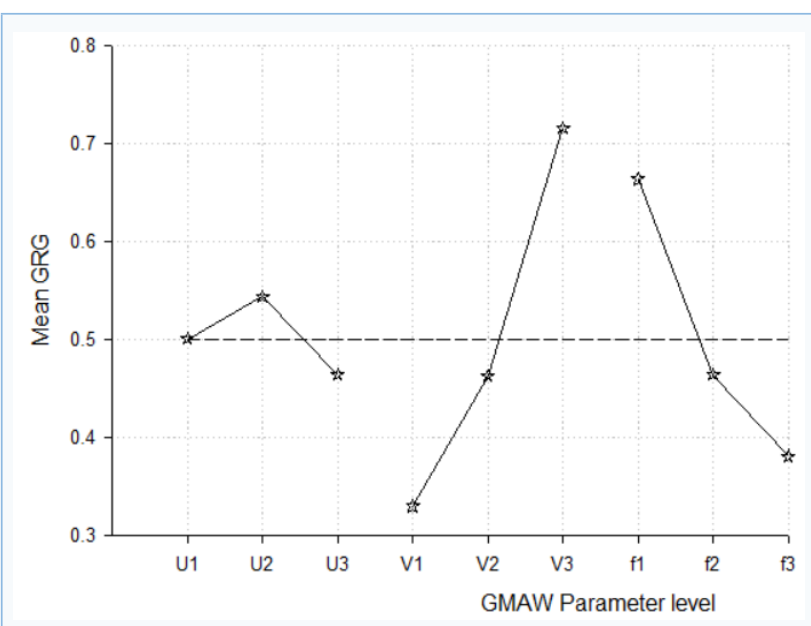

(a)

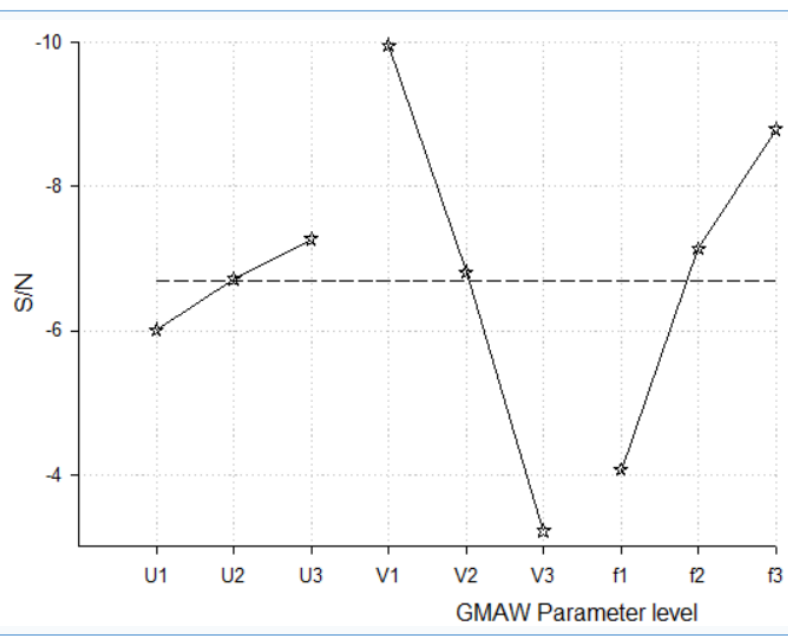

(b)

Figure 5. (a) Mean GRG, (b) S/N

Table 9. Response results for mean GRG and S/N

\begin{tabular}{|c|c|c|c|c|c|}
\hline \multirow{2}{*}{ Factors } & \multicolumn{5}{|c|}{ Mean GRG } \\
\hline & Level 1 & Level 2 & Level 3 & Delta $=\max -\min$ & Rank \\
\hline $\mathrm{U}$ & 0.501 & 0.544 & 0.464 & 0.079 & 3 \\
\hline V & 0.330 & 0.463 & 0.716 & 0.386 & 1 \\
\hline$f$ & 0.664 & 0.464 & 0.381 & 0.283 & 2 \\
\hline \multicolumn{5}{|c|}{ Total mean Grey relational grade $=0.50$} & \\
\hline \multirow{2}{*}{ Factors } & \multicolumn{4}{|c|}{$\mathrm{S} / \mathrm{N}$} & \\
\hline & Level 1 & Level 2 & Level 3 & Delta $=\max -\min$ & Rank \\
\hline$U$ & -6.006 & -6.715 & -7.270 & 1.264 & 3 \\
\hline V & -9.962 & -6.813 & -3.216 & 6.746 & 1 \\
\hline$f$ & -4.063 & -7.135 & -8.793 & 4.731 & 2 \\
\hline \multicolumn{6}{|c|}{ Total mean $\mathrm{S} / \mathrm{N}=-6.70$} \\
\hline
\end{tabular}

\subsection{The Analysis of Variance (ANOVA) Method}

The analysis of variance (ANOVA) is a useful standard statistical tool carried out to determine which parameters significantly influence on quality characteristics. Percent contribution of factors are also calculated throughout ANOVA analysis [19]. This is accomplished by separating the overall variability of the GRG, determined by the number of the square deviations from the GRG average, between the contributions and the error of each GMAW parameter. Namely;

$$
\boldsymbol{S}_{T}=S_{p}+S_{e}
$$

where

$$
\boldsymbol{S}_{T}=\sum_{j=1}^{n}\left(\gamma_{j}-\gamma_{m}\right)^{2}
$$

and

\begin{tabular}{|c|c|}
\hline $\mathrm{SS}_{\mathrm{T}}$ & Total sum of mean square deviations \\
\hline$\gamma_{j}$ & Average response related to $\mathrm{j}^{\text {th }}$ experiment \\
\hline$\gamma_{m}$ & Grand mean of the response \\
\hline $\mathrm{n}$ & Experiment run number \\
\hline $\mathrm{SS}_{\mathrm{p}}$ & Sum of square deviations for each parameters \\
\hline $\mathrm{SS}_{e}$ & Sum of squared error-related deviations \\
\hline
\end{tabular}

The F value of Fisher's ratio, which is the ratio of the mean of squares deviations of the parameters to the total mean of the error, was also used to calculate how much the parameter influences the responses. Table 10 illustrates the summary of the calculated statistical results.

Table 10. Analysis of variance results for GMAW parameters

\begin{tabular}{|c|c|c|c|c|c|}
\hline Parameter & $\begin{array}{c}\text { Degree of } \\
\text { freedom }\end{array}$ & Sum of square & $\begin{array}{c}\text { Mean } \\
\text { Square }\end{array}$ & $\mathrm{F}$ & $\begin{array}{c}\text { Contributi- } \\
\text { on (\%) }\end{array}$ \\
\hline $\mathrm{U}$ & 2 & 0.00953 & 0.00477 & 0.31 & 2.39 \\
\hline $\mathrm{V}$ & 2 & 0.23120 & 0.11560 & 7.47 & 57.99 \\
\hline $\mathrm{f}$ & 2 & 0.12698 & 0.06349 & 4.10 & 31.85 \\
\hline Residual & 2 & 0.03095 & 0.01547 & & 7.76 \\
\hline Total & 8 & 0.39866 & & & 100 \\
\hline \multicolumn{5}{|c|}{$\mathrm{S}=0.124396$ R-Sq=92.24\% R-Sq (adj)=68.95 } & \\
\hline
\end{tabular}

In accordance with the ANOVA analysis, it is evident that welding speed (57.99\% contribution), wire feed rate (31.85\% contribution) are the most effective parameter while welding voltage (2.39\% contribution) is the least effective parameter on ultimate tensile strength, joint efficiency and heat input. Figure 6 shows the percent contribution of GMAW parameters.

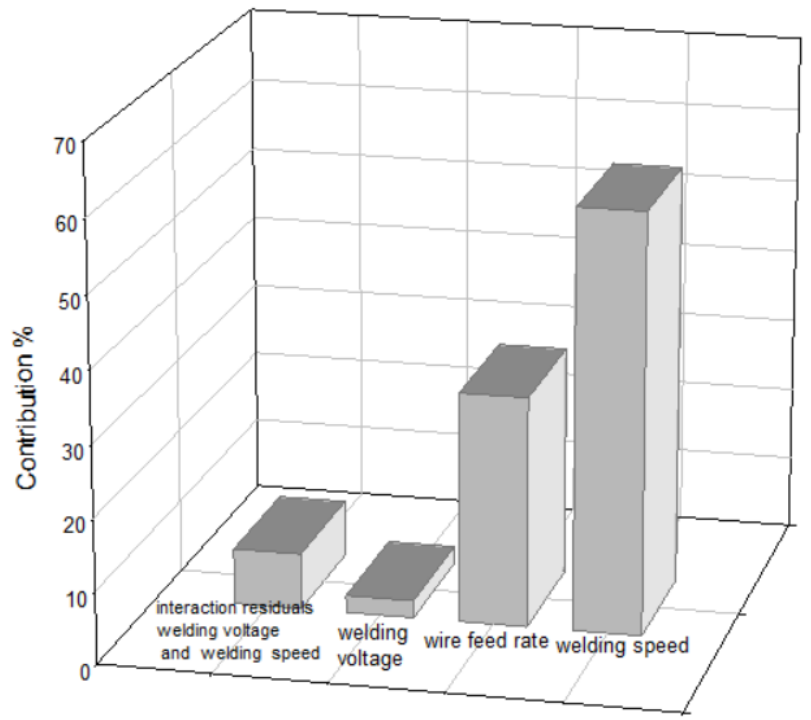

Figure 6. Contribution percentages of GMAW parameters 


\subsection{Confirmation Test}

In this work, the confirmation test is conducted at optimal parameter combination $\left(\mathrm{U}_{1} \mathrm{~V}_{3} \mathrm{f}_{1}\right)$ to verify the enhancement in the process responses and validity of the optimum welding condition. The predicted GRG $(\gamma)$ can be expressed as [19]:

$$
\hat{\gamma}=\gamma_{a}+\sum_{i=1}^{p}\left(\bar{\gamma}_{o}-\gamma_{a}\right)
$$

where $\gamma_{a}$ is the total average GRG, $\bar{\gamma}_{o}$ is the average GRG at the optimal level, and $p$ is the design parameter number $[11,19]$. Table 11 shows the confirmation test results.

Table 11. Confirmatory test results

\begin{tabular}{|c|c|c|c|}
\hline & $\begin{array}{c}\text { Initial parameter } \\
\text { set up }\end{array}$ & \multicolumn{2}{|c|}{ Optimum parameter condition } \\
\cline { 3 - 4 } & $\mathrm{U}_{1} \mathrm{~V}_{1} \mathrm{f}_{1}$ & $\mathrm{U}_{1} \mathrm{~V}_{3} \mathrm{f}_{1}$ & $\mathrm{U}_{1} \mathrm{~V}_{3} \mathrm{f}_{1}$ \\
\hline Responses & 794.125 & & 816.21 \\
\hline UTS & 0.79 & & 0.81 \\
\hline $\mathrm{JE}$ & 0.145 & & 0.099 \\
\hline $\mathrm{Q}$ & -6.63 & 0.04 & -0.10 \\
\hline $\begin{array}{c}\text { S/N ratio for overall } \\
\text { GRG }\end{array}$ & 0.46 & 0.88 & 0.99 \\
\hline $\begin{array}{c}\text { Overall GRG } \\
\text { Improvement in GRG } \\
\text { is 0.53 }\end{array}$ & & & \\
\hline
\end{tabular}

From the confirmatory test results, it is clear that improvement in overall GRG is obtained as 0.53.This is the main indicator of the proposed optimization methodology. Also, the method shows that higher UTS, JE and Q was obtained under determined optimum welding condition.

\section{CONCLUSIONS}

According to aforementioned results, this study also remarked the effectiveness of the Taguchi method on designing experiment and optimization under restricted number of experiments. It is concluded that the Grey relationship analysis based on the hybrid application of Taguchi was successful in solving a multi-criteria optimization problem. The best results for the responses of ultimate tensile strength of 816.21 MPa, joint efficiency of 0.81 and heat input of 0.099 $\mathrm{kj} / \mathrm{mm}$ are obtained for the DP1000 workpiece using the optimum welding parameters of voltage of $17.50 \mathrm{~V}$, welding speed of $380 \mathrm{~mm} / \mathrm{min}$ and wire feed rate of $2.20 \mathrm{~m} / \mathrm{min}$ under current of $45 \mathrm{~A}$. So, ultimate tensile strength, joint efficiency and heat input in gas metal arc welding process is greatly enhanced by using hybrid Taguchi based grey relation method.

\section{REFERENCES}

[1] Karatas, M. (2018). Optimization of GMAW Process Parameters for Improving Mechanical Properties of DP1000 Steel Joint, MSc Thesis. Cukurova University Institute of Natural and Applied Sciences.

[2] http://www.lincolnelectric.com (2014). Gas Metal Arc Welding. The Lincoln Electric Company, 22801 Saint Clair Avenue. Cleveland, $\mathrm{OH}, 44117$, U.S.A.

[3] Martinez R.T., Bestard, G.A., Silva, A.M.A., Alfaro, S.C.A. (2021). Anal- ysis of GMAW process with deep learning and machine learning techniques. Journal of Manufacturing Processes 62: 695-703.

[4] Huang, Y., Yang, D., Wang, K., Wang, L., Fan, J. (2020). A quality diagnosis method of GMAW based on improved empirical mode decomposition and extreme learning machine. Journal of Manufacturing Processes 54:120-128.

[5] Sivasakthivel, P.S., Sudhakaran, R. (2020). Modelling and optimisation of welding parameters for multiple objectives in pre-heated gas metal arc welding process using nature instigated algorithms. Australian Journal of Mechanical Engineering, 18: 76-87.

[6] Chauhan, M.J. (2017). Optimization of parameters for gas metal arc welding of mild steel using Taguchi's technique. International Journal of Current Engineering and Scientific Research, 4(8): 1-8.

[7] Aghakhani, M., Mehrdad, E., Hayati, E. (2011) Parametric Optimization of Gas Metal Arc Welding Process by Taguchi Method on Weld Dilution. International Journal of Modeling and Optimization, 1(3): 216-220.

[8] Kumar, A., Khurana, M.K., Pradeep, K. Y. (2016). Optimization of Gas Metal Arc Welding Process Parameters. IOP Conf. Series: Materials Science and Engineering, 149: 1-11.

[9] Rizvi, S.A., Wajahat, A. (2020). Multi attribute decision making parametric optimization in weld bead by gas metal arc welding through grey relation analysis: A case study. International Journal of Engineering, Science and Technology, 12(2): 59-66.

[10] Arya, DM., Chaturvedi V., Vimal, J. (2013). Parametric optimization of mig process parameters using Taguchi and grey Taguchi analysis, International journal of research in engineering \& applied sciences, 3(6): 2249-3905.

[11] [11] Esme, U., Bayramoglu, M., Kazancoglu, Y., Ozgun, S. (2009). Optimization of Weld Bead Geometry in Tig Welding Process Using Grey Relation Analysis And Taguchi Method. Materiali in Tehnologije, 43(3): 143-149.

[12] Srivastava, S., Garg, R.K. (2017). Process parameter optimization of gas metal arc welding on IS: 2062 mild steel using response surface methodology, Journal of Manufacturing Processes 25: 296-305.

[13] Singla M., Singh, D., Deepak, D. (2010). Parametric Optimization of Gas Metal Arc Welding Processes by Using Factorial Design Approach. Journal of Minerals \& Materials Characterization \& Engineering, 9(4): 353-363.

[14] Ambekar, S.D., Wadhokar, S.R. (2015). Parametric Optimization of Gas metal arc welding process by using Taguchi method on stainless steel AISI 410. Modern Engineering and Emerging Technology, 3(1): 1-9.

[15] Yadav, R.K., Jain, N., Thakur, K. (2015). Parametric Optimisation of Gas Metal arc Welding Process with the Help of Taguchi Method on Tensile Strength - A Review. International Journal of Engineering Research \& Technology, 4(4): 223-226.

[16] Sreeraj, P., Kannan, T., Maji, S., (2013). Optimization of GMAW Process Parameters Using Particle Swarm Optimization. ISRN Metallurgy, 2013: 1-10.

[17] Shao, Q., Xu, T., Yoshino, T., Song, N. (2017). Multi-objective optimization of gas metal arc welding parameters and sequences for low-carbon steel (Q345D) T-joint, Journal of Iron and Steel Research. Journal of Iron and Steel Research, International 21: 511- 555.

[18] Kshirsagar, R., Jones, S., Lawrence, J., Tabor, J. (2020) Optimization of TIG Welding Parameters Using a Hybrid Nelder Mead-Evolutionary Algorithms Method. Journal of Manufacturing and Materials Processing, 4(10): 1-21. 
[19] Datta, S., Bandyopadhyay, A., Kumar, P.P. (2008). Grey-Based Taguchi Method for Optimization of Bead Geometry in Submerged Arc Bead-On-Plate Welding. International Journal of Advanced Manufacturing Technology volume 39: 1136-1143.

[20] http://www.ssab.com.tr/products/brands/docol/products/docol-1000dp (2009). Welding of Domex and Docol Advanced High Strength Steels. SSAB Tunnplat AB SE-781 84 Borlange, Sweden [accessed 30 June 2018]. 